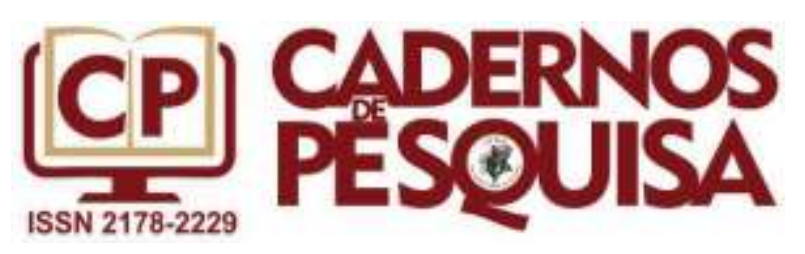

\title{
LEITURA E REPRESENTAÇÃO DE UM DRAMA: O ESPAÇO NO SISTEMA DE ENSINO ${ }^{1}$
}

\author{
LECTURA Y REPRESENTACIÓN DE UN DRAMA: \\ EL ESPACIO EN EL SISTEMA DE ENSEÑANZA
}
READING AND REPRESENTATION OF A DRAMA: SPACE IN THE EDUCATION SYSTEM

\begin{abstract}
Resumo: O presente artigo parte de um testemunho pessoal e assume deliberadamente a literatura como campo de referências e de imagens. Acredita-se que se ela serve para alguma coisa será também para nos dar testemunhos em discurso ficcional, note-se, do que são e significam espaços, volições, representações e valores, em sinuosa conexão com a nossa vida e com o nosso trânsito social. A "leitura e representação de um drama" que aqui se desenvolve implica uma problematização do espaço em função de várias dimensões, variavelmente envolvidas em práticas de ensino. Numa acepção particular que merece especial atenção, os espaços do ensino são objetos de representações literárias, modelizando fraturas sociais, culturais, pedagógicas muito importantes, também por delas serem indissociáveis valores e atitudes ideológicas.
\end{abstract}

Palavras-chave: Literatura. Espaço no sistema de ensino. Representação.

Abstract: This article starts from a personal testimony and deliberately assumes literature as a field of references and images. It is believed that if it is somehow useful, it will also be to give us testimonies, in fictional discourse, of what spaces, volitions, representations and values are and mean, in a sinuous connection with our life and with our social transit. The "reading and representation of a drama" that is developed here implies a problematization of space in terms of several dimensions, which are variably involved in teaching practices. In a particular sense that deserves special attention, teaching spaces are objects of literary representations, modeling very important social, cultural and pedagogical fractures, also because they are inseparable from ideological values and attitudes.

Keywords: Literature. Space in education system. Representation.

\footnotetext{
${ }^{1}$ Este texto foi produzido para a conferência internacional Espaços de educação, tempos de formação realizada em novembro de 2001, em Lisboa, e integra o volume de mesmo nome editado pela Fundação Calouste Gulbenkian, em maio de 2002. A referência completa da publicação original é: REIS, Carlos (2002). "Leitura e representação de um drama: o espaço no sistema de ensino". In Espaços de Educação, Tempos de Formação. Lisboa: Fundação Calouste Gulbenkian, pp. 123-139. A publicação foi autorizada pelo autor.
}

${ }^{2}$ Fundação José Saramago/Lisboa - José Saramago Foundation/Lisbon.Universidade de Coimbra 
Resumen: El presente artículo parte de un testimonio personal y asume deliberadamente la literatura como campo de referencias e imágenes. Se cree que, si sirve para algo, será también para darnos testimonios en discurso ficcional de lo que son y significan espacios, voluntades, representaciones y valores, en sinuosa conexión con nuestra vida y con nuestro tránsito social. La "lectura y representación de un drama", que aquí se desarrolla, implica una problematización del espacio en función de diferentes dimensiones, variablemente relacionadas con prácticas de enseñanza. En una acepción particular que merece atención especial, los espacios de enseñanza son objetos de representaciones literarias, modelizando fracturas sociales, culturales y pedagógicas muy importantes, también porque son indisociables sus valores y actitudes ideológicas.

Palabras clave: Literatura. Espacio en el sistema de enseñanza. Representación.

1. A minha intervenção nesta conferência "Espaços de educação, tempos de formação" parte de um testemunho pessoal. Assim tem que ser. De todos os que aderiram a esta iniciativa sou certamente o menos qualificado, se pensamos em campos de especialização como os que enquadram este colóquio: não tenho formação no campo das ciências da educação, não sou historiador, psicólogo nem sociólogo, não administro nem dirijo escolas, qualquer que seja o seu nível de inserção no sistema de ensino. Mais: neste momento nem sequer exerço a actividade de professor.

Mas fui e voltarei a ser professor e, além disso, tenho memória. Por isso aceitei dar o meu contributo, sob o signo dessa dupla condição de pedagogo (numa acepção lata do termo, bem entendido) e de sujeito com recordações e com a experiência pessoal de representações que diversamente remetem para as grandes questões que aqui estão em equação. Mais: a minha memória d e professor não anula a de aluno que também fui; e menos ainda anula, antes estimula, a de professor de literatura.

"Leitura e representação de um drama: o espaço no sistema de ensino" assume deliberadamente a literatura como campo de referências e de imagens que à sua maneira ilustram questões como as que nesta conferência se inscrevem. Se a literatura serve para alguma coisa, será também para nos dar testemunhos, em discurso ficcional, note-se, do que são e significam espaços, volições, representações e valores, em sinuosa conexão com a nossa vida e com o nosso trânsito social.

Para além disso, a minha experiência de professor tem sido orientada para o ensino da literatura portuguesa dos séculos XIX e XX, num espaço educativo especifico que é o da Universidade de Coimbra. E é bem sabido, particularmente por quantos conhecem o que chamarei imaginário da Universidade de Coimbra, que um tal imaginário não pode dispensar o suporte de certa literatura, naquilo em que esse discurso se propõe precisamente representar determinados modelos educativos e atitudes pedagógicas. Acontece isso em especial num tempo (que é o tempo do século XIX) em que relevantes mutações políticas, sociais e ideológicas incitaram a literatura a dar um contributo de intervenção crítica que não podemos ignorar, quando está em causa a subquestão a que aqui me atenho: o espaço no sistema de ensino. 
Com razão declara o texto programático desta conferência, em certo passo: "No essencial, a arquitectura do sistema de ensino mantém-se inalterada desde o final do século XIX." A memória desse tempo projecta-se no nosso, não raro, de forma dramática, sendo claro para mim que o drama de que aqui falo envolve sobretudo, em clave etimológica, acção, tensão e mesmo conflitualidade. Mais: o dramático a que me refiro decorre de um certo tipo de orientações e de imagens, propostas no documento programático que já citei e que volto a citar: "Infelizmente, em vez de uma análise séria e informada, temos assistido a um desfiar de acusações e, sobretudo, a uma reprodução de dicotomias que em nada ajudam a pensar: ensinar ou aprender, selecção ou igualdade, conhecimentos ou alunos, conteúdos ou pedagogia, elitismo ou democratização, autoridade ou liberdade, esforço ou interesse, lição magistral ou trabalho individualizado, etc. O drama da Escola é a impossibilidade de optar por um ou por outro destes gestos: a intenção de educar só se completa quando eles se encontram e se transformam num só."

No presente contexto, assume, assim, um significado especial um certo tipo de orientações propostas no documento que rege esta conferência: drama, desassossego, postulações dilemáticas, a par de difusas sugestões arquitectónicas, sendo evidente que algumas dessas imagens revelam um claro recorte artístico e literário. A "leitura e representação de um drama" que aqui desenvolvo implica uma problematização do espaço em função de várias dimensões, variavelmente envolvidas em práticas de ensino. Numa acepção particular que aqui é objecto de especial atenção, os espaços do ensino são objecto de representações literárias, modelizando fracturas sociais, culturais e pedagógicas muito importantes, também por delas serem indissociáveis valores e atitudes ideológicas.

2. É nisso mesmo que agora me centro, em função de um texto que nunca desapareceu da minha memória:

Fizemos na aula de hoje um exercício de composição em que descrevemos a nossa escola.

O sr. Professor esteve a apreciar e a corrigir os nossos trabalhos, tendo verificado que o melhor era, sem dúvida, o de Fernando Costa.

Demos os parabéns ao Fernando, que sorria satisfeito, mas com modéstia.

Eu gostei tanto do trabalho do meu condiscípulo que Ihe pedi mo deixasse copiar.

O Fernando acedeu de boa vontade ao meu pedido, e eu dei princípio à cópia:

"O edifício onde se encontra instalada a nossa escola é cheio de ar puro e de sol e fica situado a leste da nossa aldeia, num lugar aprazível.

$\mathrm{Na}$ sua frente estendem-se campos cultivados, que um ribeiro fertiliza com as suas águas claras.

A nossa escola fica na margem direita deste ribeiro; na margem oposta passa a linha do caminho de ferro, por onde transitam, diariamente, vários comboios.

A sala da aula é bastante ampla; quatro grandes janelas deixam entrar a luz e o ar. 
Em quatro filas de carteiras tornam assento os alunos. Em cima de um estrado e em frente de nós, está colocada a secretária do sr. Professor. A um lado encontra-se o quadro preto, e a seguir a caixa métrica e uma estante com livros.

Mapas corográficos, diversas gravuras com vistas de terras portuguesas e alguns desenhos feitos pelos alunos acham-se suspensos nas paredes. Ha também alguns quadros com máximas morais, e outros para o estudo das Ciências da Natureza." O sr. Professor elogiou este exercício e disse para todos nós:

— Vêem vocês?! Este trabalho está bem feito, porque foi redigido com cuidado, método e atenção.

O texto intitula-se "A nossa escola", vem naquele que foi o meu livro de leitura da quarta classe e assina-o João Ilharco, autor de diversas obras destinadas ao nosso ensino primário, nos anos 40 e 50: uma Corografia de Portugal e do Império Colonial Português, uma Gramática Portuguesa, uma História de Portugal, um livro de aritmética, outro de ciências naturais e ainda uma "iniciação da leitura e da escrita", cujo título não resistiu à tentação de uma metáfora bem pouco original: Amanhecer. Autor prolífico e diversificado, pois; tão diversificado que compôs ainda um Libelo contra a poesia modernista (de 1955, ano já tardio para libelos anti-modernistas, diga-se de passagem) e mais recentemente, em 1971, uma Fátima desmascarada, subintitulada $A$ verdadeira história acerca de Fátima, obra que conheceu várias edições e alguma reacção polémica.

O que agora me interessa é a arquitectura física e ideológica desta escola concebida por Ilharco para as crianças da minha geração. Nela, abundavam a luz as virtudes, ao mesmo tempo que escasseavam as invejas e os conflitos. A escola que o Fernando descreve, além de ampla e saudável (não se falava então de poluição), confina com a aldeia e convive com uma agricultura fertilizada por um ribeiro, não ainda por fundos comunitários. Curiosamente, a escola fica na margem direita deste ribeiro, mas ele não tem margem esquerda, tem apenas "margem oposta", essa em que circulam os "vários comboios" que incutem ao cenário rural aqui discretamente celebrado a nota de progresso relativo que parece bem registar.

Dentro da escola imperam evidentemente uma risonha disciplina e uma bem arrumada ordem: os alunos sentam-se em sólidas carteiras, não em cadeiras soltas, fabricadas com materiais sintéticos, o professor é um senhor com maiúscula - "O sr. Professor" - e com direito ao estrado e à secretária que bem demarcam o seu lugar de poder. Para que o conjunto fique acabado falta falar no "quadro preto", com a sua ardósia por certo extraída do bem português xisto, nos "mapas corográficos" (as crianças deste tempo sabiam o que queria dizer esta estranha palavra), na caixa métrica, nos livros e inevitavelmente em "alguns quadros com máximas morais". Não é necessário sequer sabermos que máximas eram estas, quando percebemos que entre o sr. Professor e os alunos fluía um diálogo de tolerância e de virtudes: o sr. Professor aprecia e corrige os trabalhos, o Fernando é modesto e o anónimo narrador deste instrutivo episódio não é invejoso. Copiar o trabalho do condiscípulo é obviamente um acto de homenagem, para proveito e elevação moral das outras crianças que pelo país fora liam este texto a vários títulos exemplar. 
Assim eram as coisas - ou assim se desejava que fossem, como será talvez mais certo dizer. No país aparentemente harmonioso e pacífico em que tudo isto transcorria, nem todas as escolas seriam arejadas e luminosas como esta (a minha não era), os ribeiros não corriam sempre na direcção certa e nem todos os meninos iam para a escola. Só a margem esquerda era oposta à direita, embora isso se não afirmasse às claras, como no texto se não diz, de facto; e talvez os meninos que conseguiam ir para a escola, justo é dizê-lo, fossem capazes de escrever com os atributos de cuidado e de correcção gramatical que a redacção do Fernando exibe, atributos que hoje, mesmo na universidade, desconhecem os Fernandos já filhos deste.

Perante um testemunho como este, em que ao mesmo tempo emergem colorações pedagógicas e notações ideológicas, é difícil não viver sentimentos contraditórios: de alguma nostalgia (que é certamente a da infância em que estas questões se não ponderavam, muito menos se discutiam), mas também de afastamento e mesmo de rejeição, efeito não apenas da passagem do tempo mas sobretudo das vivências que permitiram observar que nem todas as escolas eram assim tão arejadas, nem todos os Fernandos tão dotados para a Língua Portuguesa e nem todos os seus condiscípulos reverenciavam um tão evidente talento compositivo.

3. Parece claro que, ao encarar um espaço pedagógico nos termos em que o tenho feito, não aceito uma sua existência radicalmente objectiva, despojada de valorações e exterior tanto ao sujeito que o vive como àquele que o representa, seja essa representação da ordem da análise científica, seja ela da ordem da modelação literária. Noutros termos: a categorização do espaço como elemento presente num sistema (o sistema de ensino) não é inocente. Para além da obrigatória, óbvia e já banal menção à circunstância orteguiana que afecta o sujeito (e nessa circunstância o espaço é, evidentemente, um factor determinante, entre outros), os componentes espaciais que integram o sistema de ensino fazem-no também em função de impregnações várias; do meu ponto de vista, essas impregnações, sendo sobretudo ideológicas e difusamente culturais, devem muito ao trabalho da memória literária, essa em que se projecta um repositório de referências de que o nosso imaginário se não liberta.

Acresce a isto que, num determinado sector disso a que hoje chamamos campo literário, o espaço constitui uma categoria artística fundamental. Refiro-me às narrativas e particularmente àquelas (que são certamente preponderantes, do ponto de vista quantitativo) em se procede à descrição daquilo que é exterior às personagens, os espaços que as determinam e aqueles que por elas são condicionados, numa dinâmica de interacções que ao longo da história literária foi elaborada de formas muito diversas. Os espaços ficcionais não são, contudo, apenas espaços físicos; de certa forma, esses são talvez os menos significativos. Os espaços psicológicos, os espaços sociais, os espaços culturais, os espaços ideológicos e também os espaços pedagógicos recolhem, por esse movimento a que 
chamei de impregnação, atitudes, sentidos e valores que fazem deles não apenas metáforas enriquecidas do espaço, numa acepção mais despojada e neutralizada do termo, mas também suas derivações, de fronteiras imprecisas. O espaço enquanto categoria literária não se confunde, entretanto, com o espaço real, conforme nota Roman Ingarden, na sua descrição fenomenológica da obra literária: ele é "um espaço próprio que, por essência, pertence ao mundo "real" apresentado", mas que "não pode simplesmente ser equiparado a este": "Este espaço distingue-se precisamente do espaço real pela particularidade especial de, embora não positivamente limitado e finito, não ser contudo ilimitado no sentido em que é o espaço real" (Ingarden, 1973: 245).

O potencial semântico que caracteriza esta espécie de axiologia do espaço - uma axiologia a que não é estranha uma fenomenologia do espaço - confirma-se por aquilo que é o âmbito operatório da denominada semiótica do espaço, subdisciplina com evidentes e fecundas projecções na análise dos espaços ficcionais e numa sua derivada reflexão sobre os espaços no sistema de ensino. O que na semiótica do espaço está em causa é o desenvolvimento da chamada proxémica, em estreita relação com a antropologia cultural e interessada numa certa comunicação não verbal ou linguagem do silêncio, de acordo com a expressão consagrada de Edward T. Hall (1959): a construção de micro-espaços, as distâncias físicas entre os sujeitos da comunicação e mesmo a configuração urbanística em geral constituem elementos decisivos de uma espécie de dimensão oculta (cf: Hall, 1966) dos processos comunicativos, com inevitáveis reflexos na comunicação pedagógica. Por outro lado, a semiótica do espaço fundada na proxémica recorre ao poder heurístico dos chamados códigos arquitectónicos e aos significados que eles articulam: a sugestiva análise que Umberto Eco consagrou à cidade de Brasília (Eco, 1975: 390-394), considerando as fracturas sócio-ideológicas entre o projecto inicial e as perversões que o afectaram, mostra bem como o espaço urbano é o lugar privilegiado de formulação de discursos "silenciosos" em que se projecta, se subverte e mesmo se compromete a felicidade dos homens.

4. Assim também, mutatis mutandis, com os espaços ficcionais, entendidos como instâncias de representação de sentidos ideológicos; assim também com espaços de ensino que nas ficções se representam.

A penetração nesses espaços de ensino literariamente representados elabora-se como cerimónia iniciática que requer a entrada num lugar específico e bem delimitado, lugar físico mas também cenário de exercício de poderes: os objectos, as posições físicas das personagens, as interacções que entre elas se desenrolam são os signos e os discursos que permitem aceder a uma difusa semântica do espaço pedagógico, indissociável dos tempos culturais e dos sistemas de ensino que neles se projectam.

Conta Trindade Coelho no início do conto "Para a escola": "No velho casarão do convento é que era a aula. Aula de primeiras letras. A porta lá estava, com fortes pinceladas vermelhas, ao cima da grande escadaria de pedra, tão suave que era um regalo subi-la". 
Ao casarão fechado e que abriga a escola oitocentista d'Os Meus Amores chega a criança, como objecto cautelosamente entregue: "A encomendinha era eu, que ia pela primeira vez à escola. Ali estava a encomendinha!" (Coelho, 1986: 110)

Do exterior relativamente livre e permissivo, a criança transita, pois, para um interior disciplinado e mesmo repressivo: a escada que se sobe, a porta que se transpõe, o lugar do professor, as bancadas onde se amontoam os alunos estruturam uma rede de relações humanas simbolicamente dominada por um objecto, a palmatória. À luz dos valores vigentes, é esse instrumento de punição que faz do professor um verdadeiro artífice, alguém que labora com as suas próprias mãos e que desempenha uma tarefa apresentada como material, mais do que espiritual ou cultural: "Um mestre sem palmatória é um artista sem ferramenta, não faz nada" (Coelho, 1986: 112), declara o professor, recordado num contexto emotivo que, por fim, propicia uma representação não crítica, antes fortemente nostálgica, da escola.

A entrada no espaço do ensino coincide, assim, com os primórdios de um trajecto autobiográfico fundacionalmente marcado pela experiência da escola, da sua organização social e dos rituais que nela se encenam. N'A Criação do Mundo, Miguel Torga abre precisamente o relato com a evocação da escola do protagonista, numa infância historicamente localizada no Portugal rural e transmontano de cerca de 1915, não muito posterior ao tempo de Trindade Coelho: o lugar simbólico da escola, nesse microcosmos arcaico, nada tem de idílico, antes corresponde ao ascendente social que o "mestre" também reclama, capacitado como está para ensinar, para exercer funções administrativas e sobretudo para colher os proventos económicos que o múnus docente favorecia. E, assim, a entrada no espaço da escola, tutelado por um Sr. Botelho bem diferente do ameno e simpático professor do Fernando da minha infância escolar, exigia um tributo que condicionava os termos em que, depois, se desenrolava a relação pedagógica. Por outras palavras: pagava-se em géneros a entrada na escola: "O mestre, encabado nos socos abertos e abafado no varino de surrobeco, sempre atido ao venha a nós, recebia-nos conforme a pingadeira" (Torga, s.d.: 13). A rispidez, a intimidação psicológica e os castigos físicos completam um cenário em que ressoam as marcas da pessoal experiência torguiana:

De tarde a coisa piorava, por causa das chamadas a pedra.

- Um tanque mede dez metros de comprimento, quatro e meio de largura, e de altura três vezes a décima parte do comprimento. Quero saber quantas pipas de água comporta, tendo a pipa vinte e dois almudes, e o almude vinte e cinco litros.

Era assunto para muita pancada. Pelo tamanho do enunciado, cada um de nós calculava as bolas que lhe cabiam. Metia então inveja a primeira classe, lá longe, no fundo da sala, junto ao relógio e ao contador.

Bé-a-bá; bé-é-bé...

E nós com um bico de obra daqueles!

— Adiante... Adiante... Casca-Ihe, Silvino!

Bé-à-bá; bé-é-bé... 
O tanque ficava atestado de lágrimas. Os olhos de todos nós pareciam fontes a enché-lo. (Torga, s.d-: 17)

5. Até agora fixei-me sobretudo na análise de exemplos relativamente dispersos e assistemáticos, atestando certas representações do espaço e correlatas atitudes sociopedagógicas; e contemplei sobretudo (como, de resto, continuarei a fazer) contextos ficcionais, em que se evidenciam dois intervenientes no processo pedagógico, o professor e o aluno. Convém agora caracterizar os termos em que se articula uma específica categoria representacional, o espaço, com um conceito determinante, o de sistema, conceito que preside a um campo estruturado de actuação científica, cultural, social e política, o ensino e as complexas interacções que o dominam, nos vários níveis em que tem lugar.

Refiro-me aqui a espaço antes de mais como um concreto lugar físico, com dimensões e fronteiras materiais estabelecidas, fixando diferenças entre campos de actuação autónomos (interiores e exteriores, distâncias e proximidades), lugar em que se encontram pessoas e objectos, estabelecendo entre si conexões de diversa ordem (hierárquicas, de complementaridade, etc.). Para além disso e conforme já sugeri, entendo o espaço como conceito que pode ser objecto de derivações metafóricas, recolhendo em si elementos de ordem cultural, social, psicológica, pedagógica, etc.

O espaço pedagógico estrutura-se, por sua vez, não apenas em função da delimitação de um ou vários espaços físicos (escola, aula, biblioteca, laboratório, etc.), mas sobretudo em função da integração num sistema, o sistema de ensino. E neste, não está em causa apenas a representação e a apreensão de saberes, recorrendo-se a instrumentos, a técnicas e a discursos dotados de variáveis graus de capacitação crítica; o que nele está em causa, antes de tudo, é justamente sua postulação como sistema, isto é, como conjunto de elementos autónomos, estabelecendo entre si relações de solidária interdependência, buscando um equilíbrio dinâmico, de tal forma que a alteração de um desses elementos tende a perturbar o conjunto e, por extensão, a pôr em causa os objectivos finais para que aponta o funcionamento do sistema. Nesta acepção, o espaço constitui um elemento determinante, ainda que não decisivo só por si, de caracterização e de cabal funcionamento de um sistema de ensino finalisticamente orientado.

Acentuarei um pouco mais o princípio da interacção referida - a do espaço como elemento estrutural do sistema de ensino - , recorrendo de novo à semiótica do espaço, tal como Umberto Eco a elabora, ao proceder à classificação de diferentes códigos arquitectónicos. Para aquilo que aqui está em causa, não importa tanto considerar os códigos sintácticos (relativamente desprovidos de significado) ou os códigos semânticos, no que são as suas funções primárias, nem mesmo quanto às suas funções secundárias; interessa, sim, ter em atenção os elementos desse código que denotam "carácter distributivo", conotando ideologias do modo de viver (cf. Eco, 1975: 363) e, desse modo, condicionando directamente a dinâmica do sistema de ensino. Essas ideologias do modo de viver exercem-se, então, em diferentes espaços distributivos: os espaços de leccionação convencional e as suas 
conformações (sala de aula, anfiteatro, sala de seminário), os espaços de lazer e as suas localizações (recreio, campo de jogos, ludoteca), os espaços de aprendizagem prática, complementar ou alternativa e as funcionalidades que estabelecem (biblioteca, mediateca, laboratório, ginásio). A um outro nível, os códigos semânticos da arquitectura do ensino articulam géneros tipológicos: a escola e a sua configuração arquitectónica característica, a universidade e a sua integração urbanística, a projecção da universidade em entidades como o campus, o ajustamento da cidade a cidade universitária, numa acepção lata (Coimbra, Salamanca, Oxford, etc.) e implicando uma dinâmica social própria.

6. Regresso agora a casos selectos, isto é, à ilustração de situações histórica e culturalmente localizadas, em que encontramos antecipadas ou mesmo expressamente postuladas várias das questões que tenho ponderado. Deliberadamente situar-me-ei em momentos de fractura cultural e ideológica, esses em que se tornam mais evidentes as interacções e as tensões críticas entre elementos de um sistema de ensino, incluindo nele os elementos espaciais.

Na nossa história cultural recente, coube à chamada Geração de 70 a responsabilidade (auto-imposta, diga-se de passagem) de problematizar, em registo de crítica, diversos aspectos e instituições da vida pública do nosso século XIX: a literatura, o teatro, a política, as práticas religiosas, a memória histórica e também, naturalmente, a educação e o ensino. As Conferências do Casino, propostas e dinamizadas por Antero de Quental em 1871, e As Farpas lançadas por Eça e Ramalho Ortigão, a partir do mesmo ano, foram as manifestações mais visíveis, mas não as únicas, dessa intensa reflexão reformista. E, no que ao segundo diz respeito, importa sublinhar que os temas educativos continuaram a ocupar parte importante do seu juízo crítico, já depois de Eça ter abandonado a publicação: o volume VIII d'As Farpas (Ortigão, 1889) reúne textos sobre temas tão variados como a organização do ano escolar, os compêndios, o racionalismo na universidade, os castigos corporais, a educação das mulheres, a educação militar, a educação religiosa, a educação física, etc. Um elenco, como se vê, tão diversificado como ideologicamente significativo.

Com efeito, a atenção votada à educação e à organização do sistema de ensino reflecte, do ponto de vista da Geração de 70, sobretudo a crescente exigência de uma democratização burguesa que, indo além dos direitos e liberdades fundamentais assegurados ao cidadão na sociedade liberal, contribuísse tanto para a sua emancipação cultural, como para as solicitações e desafios de uma vida moderna cada vez mais competitiva e virada para necessidades práticas. A criação do Ministério da Instrução Pública, em 1870, as tentativas de renovação pedagógica protagonizadas por D. António da Costa, as reformas dos ensinos primário e secundário legisladas por Rodrigues Sampaio, entre 1871 e 1878, a atenção progressivamente atribuída ao analfabetismo, problema que a publicação da Cartilha Maternal de João de Deus, em 1876, procura minorar, constituem, ao longo dos anos 
70 do século $\mathrm{XIX}$, marcos muito significativos de preocupações suscitadas pelo sistema educativo e pelas suas incidências sociais e políticas (cf. Carvalho, 1986: 599 ss.).

Uma das personalidades que, nessa década de 70 , mais interesse consagrou à questão do ensino foi Adolfo Coelho: justamente "O Ensino" era o título da conferência que Adolfo Coelho proferiu no Casino Lisbonense, a 19 de Junho de 1871; mas, em diversas outras oportunidades, esse que foi também um pioneiro dos estudos filológicos em Portugal debruçou-se sobre temas pedagógicos, passada já a época das Conferências do Casino. No momento da sua conferência, Adolfo Coelho adopta a posição polémica que o evento favorecia e desenvolve a sua intervenção nos termos genéricos que as circunstâncias igualmente justificavam: trata-se de sublinhar, antes de mais, o ensino como um direito, reconhecido de forma cada vez mais alargada, direito conducente ao desenvolvimento e ao amadurecimento cultural da pessoa humana.

Mas a conferência de Adolfo Coelho não se ficou pelo plano dos princípios: recaiu também sobre problemas tão específicos como as formas e os conteúdos do ensino e a sua organização em Portugal. Como seria de esperar, foi muito crítica a posição do conferencista em relação à organização do ensino secundário e ao estado em que se encontrava a Universidade em Portugal: o primeiro é objecto de uma análise severa que incide sobre as diversas disciplinas ministradas e sobre os manuais que as apoiam; a segunda é enquadrada nas mutações ideológicas que, do ascendente dos jesuítas à reforma pombalina, foram acentuando uma falta de liberdade, no ensino e na pesquisa, que resultou em estagnação científica e em carência de espírito crítico: muito significativas, a este propósito, são as palavras de Adolfo Coelho acerca dos termos em que se processa o ensino na universidade:

Na Universidade porém predomina ainda o ensino que tem por fim a aprendizagem. Em poucas palavras direi como este é compreendido.

Há um livro de texto, um compêndio para o estudo de cada cadeira ou parte do ensino duma cadeira. A adopção desse compêndio depende da aprovação do conselho da faculdade; há assim mais alguma liberdade que nos liceus, cujos compêndios devem ser aprovados pelo governo. Esse compêndio basta; o lente ou se contenta com indicar em cada lição ao estudante as páginas que deve decorar no dia seguinte, ou explica o compêndio. A explicação do compêndio não é muitas vezes mais do que a repetição dele por outras palavras, uma simples explicação literal. Alguns professores substituem essa explicação pelo ensino de ornato, ou conciliam as duas coisas. O resultado é sempre o mesmo: o compêndio é tudo, o professor não é nada. O professor não apresenta nunca uma elaboração original, ficando assim fiel ao espírito dos estatutos. (apud Reis, 1990: 170)

As palavras de Adolfo Coelho não se referem a um espaço estritamente entendido como tal, mas apontam para um espaço educativo que não era só físico, mas sobretudo simbólico: o da universidade portuguesa, então reduzida à Universidade de Coimbra. 
7. É nesse espaço que me fixarei agora, tendo em atenção o testemunho de Eça de Queirós, elaborado sobretudo em clave ficcional, mas também em textos de índole paraliterária, evidência do que para o autor d'Os Maias foi uma preocupação constante e persistentemente crítica. É já um Eça maduro, nostálgico e por uma vez propenso à autobiografia que, no bem conhecido "Um Génio que era um Santo», in memoriam de Antero, recorda a universidade, os seus contornos físicos e o peso que exerceu sobre toda uma geração:

Em torno dela, negra e dura como uma muralha, pesando, dando sobre as almas, estava a Universidade. Por toda essa Coimbra, de tão lavados e doces ares, do Salgueiral até Celas, se erguia ela, com as suas formas diferentes de comprimir, escurecer as almas: - o seu autoritarismo anulando toda a liberdade e resistência moral; o seu favoritismo, deprimindo, acostumando o homem a temer, a disfarçar, a vergar a espinha; o seu literalismo, representado na horrenda sebenta, na exigência do ipsis verbis, para quem toda a criação intelectual é daninha; o seu foro, tão anacrónico como as velhas alabardas dos verdeais que o mantinham; a sua negra torre, donde partiam, ressuscitando o precetto da Roma jesuítica do século XVIII, as badaladas da "cabra" por entre o voo dos morcegos; a sua "chamada", espalhando nos espíritos o terror disciplinar de quartel; os seus lentes crassos e crúzios, os seus Britos e os seus Neivas, o praxismo poeirento dos seus Pais Novos, e a rija penedia dos seus Penedos! (Queirós, s.d.: 257)

A geração que assim se lamenta pela palavra de Eça é a mesma de Antero, Teófilo Braga, Guerra Junqueiro, Alberto Sampaio, Germano Meireles, João de Deus e João Penha - alguns deles, seja dito de passagem, cultivando uma mitologia da preguiça que excelentemente era justificada... precisamente pela retrógrada universidade. Seja como for, o que parece claro é que se delineia, na evocação queirosiana, uma espécie de inevitável e natural relação de dependência entre a universidade, fisicamente entendida como muralha erguida no alto da sua colina, a rigidez do seu dogmatismo e o atraso pedagógico e científico que a caracterizava. Um atraso que, de resto, tem vindo a ser pontualmente desmentido: Fernando Catroga chamou a atenção para o papel inovador de professores como José Falcão e Manuel Emídio Garcia (este último amigo e interlocutor do próprio Eça), quando se tratou de difundir o positivismo em Portugal (cf. Catroga, 1977: 28 ss.; Catroga e Carvalho, 1996: 215 ss.).

E contudo, tudo parecia estimular, na universidade oitocentista que Eça frequentou, uma aprendizagem informal de atitudes mentais divergentes em relação à ortodoxia académica propriamente dita. "A Universidade era, com efeito, uma grande escola de revolução", acentua Eça, acrescentando ainda: "E era por nos sentirmos envolvidos numa opressão teocrática que, além de pendermos para o jacobinismo, tendíamos, por puro acinte de rebeldia, para o ateísmo. De sorte que a Universidade, ultraconservadora e ultracatólica, era, não só uma escola de revolução política, mas uma escola de impiedade moral." Longe do tempo em que tudo isto se passava - a escrita do texto que tenho vindo a citar dista mais de trinta anos das vivências que reporta - é possível que o olhar memorialista de 
Eça deforme algum tanto os factos aludidos; mas não há dúvida de que muitos outros testemunhos confirmam a vocação desta geração para protagonizar, contra a universidade, as atitudes de rebeldia que valeram a Antero um processo académico e também a motivação para iniciativas como a juvenil Sociedade do Raio (cf. Nóvoa, 1991).

8. Conforme noutro local tive já oportunidade de notar, a presença de Coimbra e da sua universidade na ficção queirosiana é reiterada e a vários títulos sugestiva (Reis. 1999: 36-46). Essa presença consolidou um certo imaginário coimbrão em que o espaço - encarado aqui sobretudo como cenário de enquadramento arquitectónico e urbanístico - desempenha um papel crucial. Testemunho flagrante disso mesmo é a célebre descrição de Coimbra que se encontra n"O Primo Basílio:

\begin{abstract}
... Reclinada molemente na sua verdejante colina, como odalisca em seus aposentos, está a sábia Coimbra, a Lusa Atenas. Beija-lhe os pés, segredando-lhe de amor o saudoso Mondego. E em seus bosques, no bem conhecido salgueiral, o rouxinol e outras aves canoras soltam seus melancólicos trilos. Quando vos aproximais pela estrada de Lisboa, onde outrora uma bem organizada mala-posta fazia o serviço que o progresso hoje encarregou à fumegante locomotiva, vêde-la branquejando, coroada do edifício imponente da Universidade, asilo da sabedoria. Lá campeia a torre com o sino, que sua folgazã linguagem a mocidade estudiosa chama a cabra. Para além logo uma copada árvore vos atrai as vistas: é a celebrada árvore dos Dórias, que dilata seus seculares ramos no jardim de um dos membros desta respeitável família. E avistais logo, sentados nos parapeitos da antiga ponte, em seus inocentes recreios, os briosos moços, esperança da pátria, ou requebrando galanteios com as ternas camponesas que passam reflorindo de mocidade e frescura, ou revolvendo em suas mentes os problemas mais árduos de seus bem elaborados compêndios... (Queirós, s.d.: 328-329).
\end{abstract}

Poucas representações de Coimbra traduzem tão bem, pelo seu conteúdo também pela sua formulação, os termos em que um lugar físico se estabelece como metáfora de um poder. Recordo que estamos aqui em pleno domínio disso a que Umberto Eco chamou as ideologias do modo de viver e também no das consequências derivadas da articulação dos códigos semânticos da arquitectura, até ao ponto em que essa articulação desemboca num específico género tipológico: o da cidade universitária de extracção medieval, com as suas demarcações espaciais bem nítidas, com os seus objectos simbólicos bem caracterizados e com os seus papéis sociais bem definidos. Tudo isso e também os estereótipos que atravessam o texto citado, cujo autor não é tanto Eça de Queirós, como é o conselheiro Acácio: esta é uma descrição extraída de uma obra que o conselheiro está a escrever, a Descrição das principais cidades do Reino e seus estabelecimentos, obra cuja ponderosa seriedade é, no episódio que citei, desconstruída pela fala que abruptamente interrompe a leitura: "Está a sopa na mesa veio dizer uma criada, de avental branco, muito nutrida." 
O problema é que já encontrei esta descrição de Coimbra lida, transcrita e interpretada não como caricatura de uma mentalidade, mas como homenagem séria de um autor a uma cidade, à sua universidade e implicitamente ao sistema de ensino que ela representa. O que significa não apenas que a ironia, como se sabe, é insidiosa, mas também que não poucos continuam a conviver muito bem com aqueles estereótipos e com o que eles representam: no fundo, aquela Coimbra antecipa a que encontramos n'A Colina Sagrada, tal como, sem ironia mas com evidente propósito ideológico, a descreveu Manuel Ribeiro. Escritor hoje esquecido (e talvez mesmo justamente esquecido, apesar do relativo sucesso que no seu tempo conheceu), Manuel Ribeiro chega ao alto da sua Colina Sagrada depois de um trajecto ideológico no mínimo agitado e ecléctico, que vai do anarco-sindicalismo dos inícios do século XX, até posições anti-liberais e nacionalistas, revelando na sua Colina Sagrada (de 1925), segundo Óscar Lopes, "todas as características da literatura pré-fascista europeia" (Lopes, 1987: 406). O Jorge que no capítulo V do romance deambula pela alta coimbrã amplifica o registo enfático das páginas da Descrição das principais cidades do Reino, acrescentando-lhe uma candura apologética a que nem o conselheiro Acácio se atrevera:

\begin{abstract}
Todos os grandes de Portugal tinham ali ensaiado as asas; em Coimbra haviam rebrilhado seus cunhos de moeda nova, antes de correrem no giro vulgar da celebridade. Ali suas mentes se tinham feito, seus cérebros desabrochado, suas ideias tomado corpo; e muitos só eram grandes porque Coimbra era bela, e só tinham sido artistas porque havia em Coimbra a paisagem. Vindas dos quatro cantos do país, todas as vozes portuguesas palpitavam ali juntas, e esse solo de Coimbra era feito da poeira de todas as províncias de Portugal. Sentir a alma de Coimbra era pois sentir na sua máxima pureza a alma bela da pátria. Por sua vez, Coimbra revivia em saudades e lembranças nos corações esparsos pela terra lusíada. Sua paisagem e sua beleza dormiam amorosamente no fundo de muita cansada pupila. Como não admirar Coimbra, como não amar Coimbra! (Ribeiro, 1925: 81-82).
\end{abstract}

9. Deixo de lado o entusiasmo consagrado ao espaço de Coimbra e à sua arquitectura do saber e do poder conjugados, bem distantes da imagem que, alguns anos depois, Fernando Namora elaborou em Fogo na Noite Escura (de 1943). E regresso a Eça, dando atenção à sua ficção, essa mesma em que abundam as experiências educativas e a sua correlação com os espaços que as enquadram.

Em dois romances de publicação póstuma - A Capital! e O Conde de Abranhos são evidentes ecos autobiográficos que lembram textos evocativos como o já citado "Um Génio que era um Santo" e também o póstumo "O ‘Francesismo'”. Em ambos os romances (mas sobretudo no primeiro), o trajecto coimbrão das personagens Artur Corvelo e Alípio Abranhos não corresponde a uma experiência de séria aprendizagem e de maturação académica, mas antes a um tempo de boémia e de sujeição a um sistema de ensino autocrático e propenso ao "literalismo [da] horrenda sebenta". A isso e também a uma atitude que 
fica para a vida e que outra personagem queirosiana, o Teodoro d'O Mandarim, definiu nestes termos: "Infelizmente corcovo - do muito que verguei o espinhaço, na Universidade, recuando como uma pega assustada diante dos senhores lentes" (Queirós, 1992: 83).

Pedro da Maia não vergou o espinhaço na universidade porque não chegou lá. A pouca formação escolar que se lhe conhece é privada e ferreamente religiosa: sob a influência da mãe Maria Eduarda Runa, o Pedrinho não frequenta um colégio inglês, como Afonso da Maia queria, mas submete-se à cartilha ensinada pelo padre Vasques, na clausura do quarto dos estudos:

O Vasques ensinava-Ihe as declinações latinas, sobretudo a cartilha: e a face de Afonso da Maia cobria-se de tristeza, quando ao voltar de alguma caçada ou das ruas de Londres, de entre o forte rumor da vida livre - ouvia no quarto dos estudos a voz dormente do reverendo, perguntando como do fundo de uma treva:

— Quantos são os inimigos da alma?

E o pequeno, mais dormente, lá ia murmurando:

— Três. Mundo, Diabo e Carne...

Pobre Pedrinho! Inimigo da sua alma só havia ali o reverendo Vasques, obeso e sórdido, arrotando do fundo da sua poltrona, com o lenço do rapé sobre o joelho... (Queirós, s.d.: 18).

Em ruptura com este modelo educativo, difusamente responsabilizado pela perdição de Pedro da Maia, Carlos da Maia terá tudo o que seu pai não tivera: tutor inglês, espaços abertos, línguas vivas, exercício físico e depois, inevitavelmente, a Universidade de Coimbra. Não, contudo, o estudo do Direito que a sua condição e os usos da época aconselhavam, mas antes o da Medicina, que o orientaria para uma desejada (mas depois falhada) vida profissional activa.

O que interessa notar, entretanto, é que o espaço académico de Coimbra é, de novo, um espaço em que parece falhar a inserção num sistema educativo exigente. A sua aparente falta é, então, compensada pelo espaço alternativo da tertúlia, marcado agora pela origem social e económica de quem o institui:

\footnotetext{
Os Paços de Celas, sob a sua aparência preguiçosa e campestre, tornaram-se uma fornalha de actividades. No quintal fazia-se uma ginástica científica. Uma velha cozinha fora convertida em sala de armas - porque naquele grupo a esgrima passava como uma necessidade social. À noite, na sala de jantar, moços sérios faziam um whist sério: e no salão, sob o lustre de cristal, com o Figaro, o Times e as revistas de Paris e de Londres espalhadas pelas mesas, o Gamacho ao piano tocando Chopin ou Mozart, os literatos estirados pelas poltronas - havia ruidosos e ardentes cavacos, em que a Democracia, a Arte, o Positivismo, o Realismo, o Papado, Bismarck, o Amor, Hugo e a Evolução, tudo por seu turno flamejava no fumo do tabaco, tudo tão ligeiro e vago como o fumo. E as discussões metafísicas, as próprias certezas revolucionárias adquiriam um sabor mais requintado com a presença do criado de farda desarrolhando a cerveja, ou servindo croquetes. (Queirós, s.d.: 90)
} 
Outro espaço, portanto. E outras aprendizagens também, porventura semeando os embriões de uma atitude dispersiva e instável que o futuro da personagem confirmará de forma trágica. Não é isso que importa, neste momento. O que me interessa observar é que este espaço alternativo de boémia não anula o outro, o das obrigações académicas e o dos lentes caturras, permeáveis, contudo, a argumentos puramente sociais: Carlos da Maia "no segundo ano levaria um R se não fosse tão conhecido e rico", diz-se no romance. E é precisamente em função dessa lógica social que, por fim, a personagem reentra no lugar fechado e restrito das formalidades académicas, como refere uma expressiva e por isso muito significativa metáfora espacial: "Acantoou-se mais na ciência que escolhera: imediatamente lhe deram um accessit" (Queirós, s.d.: 90).

10. Recordo alguma coisa do que ficou antes dito, para rapidamente terminar e abrir caminho a outra coisa - a outros espaços.

Falou-se aqui de espaços pedagógicos e dos seus modos de existência. E falou-se sobretudo de lugares bem delimitados, nalgum caso até pela imponência da muralha que divide, que separa e que aparenta proteger do inimigo que supostamente está fora e quer entrar. Falou-se ainda da fixidez de papéis que nesses espaços se acolhem, o professor e o aluno, o estudante e o futrica, situados onde lhes compete estar, uns dentro, outros fora, uns no alto do estrado, outros no anonimato da bancada, uns acatando objectos, atitudes e rituais que nesses espaços se desenrolam, outros fazendo vigorar códigos de procedimento rígidos; e falou-se ainda de poderes que os espaços favorecem e estimulam, de processos pedagógicos eminentemente presenciais e autoritários, processos em que se prolongam e se institucionalizam específicas políticas de ensino.

É esta arquitectura do sistema de ensino que aqui questionamos, sobretudo quando nos apercebemos de que a noção de espaço (tal como a tradição...) já não é o que era. $O$ espaço real da sala de aula convencional possuía a segura tangibilidade das coisas concretas e visíveis; mas esse espaço real dá lugar agora ao espaço virtual, espaço sem peso nem densidade que se vejam ou sintam. O que vigora nesse espaço virtual, resultado directo do poder transformador das tecnologias da informação e da comunicação, é a fluidez e a volatilidade dos saberes, movendo-se nas imperceptíveis autoestradas da informação; é a rapidez dos hipertextos disseminados em redes, sem autoria certa nem fronteiras precisas; são os modos de ser digitais que geram livros sem páginas; é o espaço global em detrimento do espaço local; é a informação múltipla e interactiva substituindo a informação unívoca e unidireccional.

Declara Nicholas Negroponte, analisando o ser digital: "A mudança de átomos para bits é irrevogável e imparável" (Negroponte, 1996: 4). Com essa mudança confirma-se a rearticulação dos espaços educativos, trivialmente levada a cabo já, desde há anos, pelo ensino a distância, mais recentemente pelas bibliotecas digitais. Em ambos, torna-se evidente que a categorização do espaço não obedece aos mesmos princípios estruturantes 
que dominavam a escola de Trindade Coelho ou a de Torga, a universidade de Eça ou mesmo a sala de aula tão metodicamente descrita pelo Fernando da minha memória de infância.

Menos triviais e então mais ousadas eram as previsões que, há mais de quinze anos, enunciava Italo Calvino, no momento em que fazia sentido formular Seis Propostas para o Próximo Milénio, este mesmo em que estamos já. Delas ressalto propriedades que são as dos espaços virtuais em que algum ensino se processa já e em que cada vez mais se processará.

Uma: leveza. A escola do futuro já presente será mais leve — ou será até destituída de peso - ao mesmo tempo que ocupará menos espaço e será eminentemente dinâmica, pois que gozará da capacidade de estar em todos os lugares ao mesmo tempo. A leveza de que fala Calvino no seu magistral ensaio deve-se à informática, particularmente àquilo que nela é linguagem digital: "É verdade", diz Calvino, "que o software não poderia exercer os poderes da sua leveza senão por meio do peso do hardware; mas é o software que comanda, que actua sobre o mundo exterior e as máquinas, que só existem em função do software, evoluindo de modo a elaborar programas mais complexos". Nesta nova revolução industrial "continuam a existir máquinas de ferro, mas obedecem aos bits sem peso" (Calvino, 1990: 22).

Outra propriedade: velocidade. A escola do futuro será cada vez mais veloz, porque as máquinas e as linguagens de que dispomos já hoje apontam claramente nesse sentido: rapidez de troca de saberes, rapidez de acesso à informação, rapidez de transferência de suportes. Calvino adverte, contudo: "O tema que nos interessa aqui não é a velocidade física, mas sim a relação entre a velocidade física e a velocidade mental" (Calvino, 1990: 57). É nesse sentido último no da velocidade mental, que a escola se orientará, porque é a rapidez do conhecimento, com a sua incessante caducidade e poder de renovação, que por fim a motiva e determina a sua existência.

Terceira propriedade: multiplicidade. "O conhecimento como multiplicidade", escreveu Calvino, "é um fio condutor que liga as obras maiores, tanto do que se designa por modernismo como daquilo a que se chama pós-moderno, um fio que (...) eu desejaria ver desenrolar-se no próximo milénio" (Calvino, 1990: 137) Obras maiores são naturalmente as que à escola devem interessar, como testemunho da memória cultural e artística; obra maior deverá ser a própria escola, reconstruída sob o signo dessa multiplicidade — de funções, de linguagens, de instrumentos, de especialidades e de comportamentos - que há-de exigir a quem nela trabalhar a aceitação serena dessa mesma noção de multiplicidade. 


\section{REFERÊNCIAS BIBLIOGRÁFICAS}

CALVINO, Italo. Seis Propostas para o Próximo Milénio. Lisboa: Teorema, 1990.

CARVALHO, Rómulo de. História do Ensino em Portugal. Lisboa: Fundação Calouste Gulbekian, 1986.

CATROGA, Fernando. Os inícios do Positivismo em Portugal. O seu significado político-social, in Revista de História das Ideias, vol. 1, 1977.

CATROGA, Fernando; CARVALHO, Paulo Archer de. Sociedade e Cultura Portuguesas II. Lisboa: Univ. Aberta, 1996.

COELHO, Trindade. Os Meus Amores, $2^{\text {a }}$ ed. Lisboa: Ulisseia, 1986.

ECO, Umbero. La estructura ausente. Introducción a la semiótica. Barcelona: Editorial Lumen, 1975.

HALL, E. T.. The Silent Language. Greenwich: Fawcett, 1959.

. The Hidden Dimension. Garden City: Anchor Books, 1966.

INGARDEN, R.. A Obra de Arte Literária. Lisboa: Fundação Calouste Gulbenkian, 1973.

LOPES, Óscar. Entre Fialho e Nemésio. Lisboa: Imprensa Nacional-Casa da Moeda, 1987.

NEGROPONTE, Nicholas. Being Digital. New York: Vintage Books, 1996.

NOVOA, António. Em nome da liberdade, da fraternidade e da emancipação da Academia", in Revista de História das Ideias, vol. 13, 1991, pp. 231-270.

ORTIGÃO, Ramalho. As Farpas. Os nossos filhos. Instrução Pública, vol. VIII. Lisboa: Comp. Nacional Editora, 1889.

QUEIRÓS, Eça de. Os Maias. Lisboa: Livros do Brasil, (s.d.).

O Mandarim. Lisboa: Imprensa Nacional-Casa da Moeda, 1992.

QUEIRÓS, Eça de. Notas Contempoâneas. Lisboa: Livros do Brasil, (s.d.).

QUEIRÓS, Eça de. O Primo Basílio. Lisboa: Livros do Brasil, (s.d.).

REIS, Carlos. As Conferências do Casino. Lisboa, Publicações Alfa, 1990.

—.Estudos Queirosianos. Ensaios sobre Eça de Queirós e a sua Obra. Lisboa, Presença, 1999.

RIBEIRO, Manuel. A Colina Sagrada. Lisboa: Guimarães Editora, 1925.

TORGA, M. A Criação do Mundo, I, Coimbra, Edição do Autor, s.d. 